ciée de recherches zootechniques INRAENESAD, BP 1607, 21036 Dijon cedex, France)

Des résultats d'études comparatives récentes indiquent que l'âne ingère et digère mieux les fourrages pauvres que les chevaux et les poneys. La présente étude tente de situer cette aptitude de l'âne par rapport aux capacités digestives du mouton, modèle souvent utilisé chez les ruminants.

Trois fourrages, un foin de luzerne/dactyle (FLD), un foin de prairie naturelle (FP), et une paille de blé (PB) dosant respectivement (en $\% \mathrm{MS}$ ) : 17-9-3 de MAT, 51-66-76 de NDF, et 3538-45 d'ADF ont été distribués ad libitum après hâchage à 6 moutons et à 3 ânes adultes d'un poids moyen respectif de 80 et $220 \mathrm{~kg}$. Les quantités ingérées et la digestibilité de chaque fourrage ont été déterminées in vivo au cours de 3 périodes successives après 3 sem d'adaptation à chaque régime et comportant $10 \mathrm{j}$ de mesures chez les moutons et $6 \mathrm{j}$ chez les ânes. Avec le régime FLD, la digestibilité de la matière organique (DMO) est restée identique chez les 2 espèces $(60,3 \% \pm 3$ chez le mouton, $61,2 \% \pm 2$ chez l'âne) bien que les quantités de $M O$ ingérées (MOI) aient été plus élevées $(P<0,05)$ chez les ânes que chez les moutons $\left(77 \pm 5,1 \mathrm{~g} / \mathrm{kg} \cdot \mathrm{P}^{0,75}\right.$ contre $56,7+10,4 \mathrm{~g} / \mathrm{kg} \cdot \mathrm{P} 0,75)$. En revanche, la $\mathrm{DMO}$ enregistrée avec les régimes $\mathrm{FP}$ et $\mathrm{PB}$ a révélé une capacité plus grande $(P<0,05)$ des moutons à digérer les fourrages pauvres $(56,5 \pm$ 3,5 et $50,9 \% \pm 4,2$ contre $51,7 \pm 1,6$ et $44,5 \% \pm$ 4 chez l'âne, respectivement pour FP et PB), mais le bilan comparé entre les 2 espèces de la matière organique digestible ingérée $(\mathrm{MODI}=$ $\mathrm{MOI} \times \mathrm{DMO}$, exprimée en $\left.\mathrm{g} / \mathrm{kg} . \mathrm{P}^{0,75}\right)$ a révélé une nette supériorité des ânes $(P<0,01)$, par suite d'une consommation plus élevée $(47,1 \mathrm{~g} \pm$ $3,9,40 \mathrm{~g} \pm 3,6$ et $24,4 \mathrm{~g} \pm 3,8$ contre $34,3 \mathrm{~g} \pm$ $6,7,25,3 \mathrm{~g} \pm 4,1$ et $14 \mathrm{~g} \pm 3$ pour le mouton, respectivement avec FLD, FP et PB). Enfin, les moutons ont perdu en moyenne $5 \%$ de poids vif tandis que celui des ânes est resté quasi stable $(-0,7 \%)$. Au total, ces observations semblent témoigner d'une meilleure valorisation des fourrages pauvres chez les ânes.

\section{Utilisation comparée du foin et de la paille agglomérés chez le poney et l'âne.} B Suhartanto, JL Tisserand, F Faurie (Unité associée de recherches zootechniques

\author{
INRA-ENESAD, BP 1607, 21036 Dijon \\ cedex, France)
}

Afin de mettre en évidence une éventuelle supériorité des ânes sur les poneys pour l'utilisation des parois des fourrages pauvres, nous avons distribué, à 6 poneys et 6 ânes adultes (poids vif moyen 255 et $205 \mathrm{~kg}$ ), dont 3 sujets de chaque espèce étaient porteurs d'une canule de cæcum, 2 fourrages agglomérés : un foin (\% MS : MAT : 15,4 ; NDF : 57,4 ; ADF : 37,0 ) et une paille ( $\%$ MS : MAT : 5,6 ; NDF : 74,6 ; ADF : 43,6 ), en quantité limitée aux besoins de l'entretien. Nous avons mesuré la digestibilité in vivo pendant une période de $6 \mathrm{j}$ après $2 \mathrm{sem}$ d'accoutumance. Alors que l'ingestion est la même avec $57,3 \pm 0,8$ et $58,7 \pm 0,5$, et $47,8 \pm 3,8$ et $49,8 \pm 0,7$, respectivement chez les poneys et les ânes, pour le foin et la paille, la consommation de matière organique digestible par $\mathrm{kg}$ de poids métabolique $\left(\mathrm{P}^{0,75}\right)$ est inférieure chez le poney par rapport à l'âne $(26,7 \pm 4,5$ et $30,1 \pm 0,6$ pour le foin, et $18,5 \pm 1,1$ et $22,3 \pm 1,3$ pour la paille) car la digestibilité de la matière organique est plus faible.

Si la digestibilité de la fraction ADF est la même dans le cas du foin $(42,2 \pm 2,2$ et $42,6 \pm 1,7$ pour le poney et l'âne), elle est significativement inférieure chez le poney pour la paille $(34,8 \pm 2,8$ et $44,9 \pm 5,1$ chez le poney et l'âne).

Pour les 2 fourrages, la teneur en acides gras volatils du contenu du cæcum (mmoles/litres) est significativement inférieure chez les poneys par rapport à l'âne $(42,6 \pm 8,1$ contre $64,2 \pm 6,4$ pour le foin, et $30,8 \pm 5,2$ contre $71,6 \pm 7,0$ pour la paille).

Ces résultats contribuent à montrer que l'âne est plus apte à utitiser les fourrages pauvres que les poneys.

Comparaison de la dégradabilité ruminale de 4 fourrages méditerranéens chez la vache et le mouton. JL Tisserand, F Faurie (Unité associée de recherches zootechniques INRA-ENESAD, BP 1607, 21036 Dijon cedex, France)

La comparaison de la dégradabilité in sacco de fourrages méditerranéens est effectuée sur 3 vaches jersiaises adultes, taries et sur 6 moutons mâles castrés adultes, croisés Charollais $x$ Berrichon du Cher, pour tenter de proposer une méthode de mesure adaptée aux conditions de la rive sud de la Méditerranée. 